\title{
A STUDY OF URINE FROM HIV-POSITIVE AND HIV-NEGATIVE INDIVIDUALS AT ANDHRA PRADESH
}

\author{
GUNDALA OBULESU ${ }^{1 *}$, HANUMANTHAPPA AR ${ }^{2}$, PRABAKAR REDDY E ${ }^{3}$
}

${ }^{1}$ PhD scholar, Department of Medical Microbiology, Bharath University, Chennai, Tamil Nadu, India. ${ }^{2}$ Department of Microbiology, J.J.M. Medical College, Davangere, Karnataka, India. ${ }^{3}$ Department of Biochemistry, Sri Lakshmi Narayana Institute of Medical Sciences, Puducherry, India. Email: obulesu100@gmail.com

Received: 26 April 2017, Revised and Accepted: 17 May 2017

ABSTRACT

Objective: The aim of this study is to investigate the variations, if any, in urinary bacterial pathogens in HIV-positive and HIV-negative individuals.

Methods: Urine sample, macroscopic and microscopic examination for identification of bacteria use by method of Standard loop method, using identification methods, Grams-staining, Biochemical tests.

Results: Out of 75 HIV-positive males, 52 males were married, 23 males were unmarried; risk factors are sexually 28, occupationally majority were labor, 31, age group more in 19-25 age, only 9 HIV-positive patients presented with symptoms of urinary tract infection, Escherichia coli was the most frequently occurring bacterial isolate from positive urine culture followed by Klebsiella spp.

Conclusion: The study period of 1 year and 8 months revealed that it is difficult to locate/identify an HIV-positive person in a place like Kadapa on account of confidentiality/lack of awareness among the population. Having identified the HIV-positive cases, collection of urine samples from the patients also needed counseling and intervention by the respective clinicians, especially when patients were not having any symptoms. Out of 50 HIVnegative individuals, only $1(2 \%)$ urine sample is showing significant bacteriuria.

Keywords: Urinary tract infection, HIV, AIDS, Bacteria, Antiretroviral therapy.

(C) 2017 The Authors. Published by Innovare Academic Sciences Pvt Ltd. This is an open access article under the CC BY license (http://creativecommons. org/licenses/by/4. 0/) DOI: http://dx.doi.org/10.22159/ajpcr.2017.v10i6.19376

\section{INTRODUCTION}

While the genitourinary system is both a primary site of HIV infection as well as a site for its complications, yet the genitourinary tract is generally protected. According to miles and associates, urinary tract infections (UTIs) occur in $17 \%$ of patients while there was a $16 \%$ incidence of urology-related symptoms. Symptoms of UTIs include dysuria, frequency, urgency, fever, and hematuria, but many patients are relatively asymptomatic. Although, infection may be present cultures are often negative. Most AIDS patients take prophylactic antimicrobials for opportunistic infections causing pneumonia or diarrhea and this renders culture negative [1].

The reported incidence of bacterial UTI in patients with AIDS is $7-50 \%$. Bacterial infections are more common in AIDS patients with $\mathrm{CD}_{4}+$ count of $<200 / \mu \mathrm{l}$. In patients with low $\mathrm{CD}_{4}+$ counts, neurological symptoms may also occur. Bladder reflexia or hyporeflexia is a common neurological complication, which leads to urinary stasis and ultimately UTI. The most common bacterial pathogens in HIV-infected patients are Escherichia coli, Enterobacter (Enterococci), Pseudomonas, Group D Streptococcus, Proteus spp., Klebsiella, Acinetobacter, and Staphylococcus aureus [2].

\section{METHODS}

The present study was conducted from July 2014 to December 2016 in Fathima Institute of Medical Sciences (FIMS), Kadapa.

\section{Study group}

A total of 75 HIV reactive (positive) patients (age 15-59 years) were identified with the help of clinicians of Regional Institute of Medical Sciences (RIMS) and FIMS, Kadapa. These patients were being treated by the clinicians for recurring ailments. The study group comprised 55 male and 20 female HIV-positive patients.

\section{Control group}

A total of 50 HIV non-reactive individuals (34 male and 16 female), aged 18-60 years, admitted in RIMS and FIMS, Kadapa for various ailments in surgical wards were included in the study as control group. Urine samples were collected from these patients after collecting relevant information such as age, sex, occupation, present complaint, whether on ART (antiretroviral therapy), and treatment given. Urine samples were also collected with or without the presence of symptoms of UTI.

Total number of urine samples examined $=125$

\section{Laboratory diagnosis of HIV infection}

The HIV-positive cases included in this study were identified through the clinicians who were treating them for their recurrent ailments. They were investigated and identified as HIV reactive by serological tests was done elsewhere. All of the patients were reported ELISA positive (as per WHO strategy-II 1993) for HIV-1/HIV-2 with at least two different kits [1].

The individuals included under the control group were screened for their HIV status in our laboratory by ELISA and TRIDOT (J. Mitra and co. Ltd, New Delhi) [3]. Patient admitted in RIMS and FIMS period 2014 to 2016.

Sample

A clean-catch midstream urine sample was collected in a wide mouth sterile container and examined within 2-3 hrs of collection.

\section{Urine sample}

Naked eye examination of urine sample was done and any relevant finding was noted. 
Microscopic examination of urine

A wet film was prepared with a drop of urine and examined under the microscope for pus cells, RBC, organisms, etc.

\section{Culture}

Semiquantitative culture method - semiquantitative technique of inoculation in suitable culture media - by standard loop method was done to determine significant bacteriuria.

\section{Culture media used}

Maconcy agar, Blood agar , Lactose sugars bilesalt, neutralred all related biochemical reactions used.

\section{Standard loop method}

An inoculating loop of standard dimension was used to take up fixed and known volume of uncentrifuged urine and spread it over a plate of culture medium. A nichrome wire of 28 SWG was used to make a circular loop of $1 \mathrm{~mm}$ of internal diameter. It can hold $0.002 \mathrm{ml}$ urine.

Total viable bacterial count $/ \mathrm{ml}$ of sample $=$ No of colonies $\times 500$

Culture medium plate was touched with the loop containing urine from where inoculum was spread in a straight line across the diameter of plate. Without flaming, loop was drawn across entire plate, crossing the first inoculum streak numerous times to produce isolated colonies.

Inoculated plates were incubated overnight at $37^{\circ} \mathrm{C}$ in an incubator and colony count was noted.

\section{Kass concept}

In the presence of active UTI, the urine will contain $10^{5}$ bacteria or more per milliliter. This level is therefore considered to represent significant bacteriuria.

\section{Identification of the organism}

A single well-isolated colony was picked up with a sterile wire to prepare a pure subculture and the identification of the organism was done on the basis of:

- Gram staining,

- Motility test by hanging drop,

- Biochemical tests (catalase, oxidase, IMViC, urease and sugar fermentation tests, etc.), following the procedures mentioned in [4].

\section{RESULTS}

Out of 75 HIV-positive patients, 12 patients showed significant bacteriuria and was diagnosed to have UTI. The remaining cultures were sterile. No lesser counts were noted. Only one case of UTI was found in the group of HIV-negative individuals. Chi-square test revealed a statistically significant relationship between HIV status and UTI $\left(\chi^{2}=6.310, \mathrm{df}=1,0.01<\mathrm{p}<0.02\right)$ (Tables $\left.1-3\right)$

Symptoms of UTI present in HIV-infected patients are shown in Table 4. Only 9 HIV-positive patients presented with symptoms of UTI

Escherichia coli was the most frequently occurring bacterial isolate from positive urine culture followed by Klebsiella spp. (Table 5).

\section{DISCUSSION}

It shows the presence of risk factors, marital status, and occupation of 75 HIV-positive patients. In our study group, maximum patients were laborer (41\%). Promiscuity appeared to be the highest risk factor among the study group. Among the 55 male patients, only 6 patients had circumcision, whereas 49 patients were uncircumcised. As the socioeconomic status of our study group was very poor, so we were unable to get information on the $\mathrm{CD}_{4}+$ count of the patients. For four patients, the $\mathrm{CD}_{4}+\mathrm{T}$-lymphocyte count done elsewhere were recorded and all of them were above $200 / \mu$ l. Hence, the relation between CD4+ count and presence of intestinal parasites could not be established. The
Table 1: Risk factors, marital status, and occupation of 75 HIV-positive patients

\begin{tabular}{lc}
\hline Variable & n (\%) \\
\hline Marital status & 52 \\
Married & 23 \\
Unmarried & \\
Risk factors & 21 \\
Promiscuity & 08 \\
Blood transfusion & 01 \\
Intravenous drug users & 28 \\
Others (previous operation, spouse of HIV-positive & \\
person) & \\
Occupation & 06 \\
Driver & 31 \\
Laborer & 15 \\
Vendor & 04 \\
Student & 19 \\
Others & \\
Circumcision in male & 06 \\
Circumcised & 49 \\
Uncircumcised & \\
\hline
\end{tabular}

Table 2: Age- and sex-wise distribution of HIV-positive patients with intestinal parasites

\begin{tabular}{llllll}
\hline \multirow{2}{*}{ Age (years) } & \multicolumn{2}{l}{$\begin{array}{l}\text { Total number of } \\
\text { patients }\end{array}$} & & \multicolumn{2}{l}{ Parasites detected } \\
\cline { 2 - 3 } \cline { 5 - 6 } & Male & Female & & Male & Female \\
\hline $15-25$ & 19 & 04 & & 02 & 01 \\
$26-35$ & 16 & 03 & & 02 & 03 \\
$36-45$ & 11 & 08 & & 02 & 02 \\
$46-55$ & 08 & 05 & & 01 & 00 \\
$>55$ & 01 & 00 & & 00 & 00 \\
Total & 55 & 20 & & 07 & 06 \\
\hline
\end{tabular}

Table 3: Symptoms of UTI and HIV status

\begin{tabular}{lll}
\hline HIV status & HIV-positive & HIV-negative \\
\hline Symptoms of UTI present & 09 & 00 \\
No symptoms of UTI & 66 & 50 \\
Culture positive $>10^{5}$ colony $/ \mathrm{ml}$ of & 12 & 01 \\
urine & & \\
\hline
\end{tabular}

Table 4: Symptoms of UTI present in HIV-positive patients

\begin{tabular}{lll}
\hline Urinary symptoms & Male & Female \\
\hline Fever & 02 & 01 \\
Dysuria & 03 & 01 \\
Frequency & 02 & 02 \\
Suprapubic pain & 00 & 01 \\
No symptoms of UTI & 50 & 16 \\
\hline
\end{tabular}

Table 5: Bacterial isolates from positive urine culture

\begin{tabular}{llll}
\hline Bacterial isolates & \multicolumn{2}{l}{$\begin{array}{l}\text { HIV-positive } \\
\text { patients with UTI }\end{array}$} & Total (12) \\
\cline { 2 - 3 } & Male & Female & \\
\hline Escherichia coli & 04 & 04 & $08(66.7)$ \\
Klebsiella & 02 & 00 & $02(16.7)$ \\
Pseudomonas aeruginosa & 01 & 00 & $01(08.3)$ \\
Staphylococcus aureus & 00 & 01 & $01(08.3)$ \\
\hline
\end{tabular}

earlier study showed that intestinal opportunistic protozoal infection and diarrhea are more common in patients with low CD4+ count [5-7]. 
In our study of urine sample from $75 \mathrm{HIV}$-positive patients, 12 samples showed significant bacteriuria and diagnosed to have UTI. Among the 75 patients, 9 patients had symptoms of UTI which is given in Table 4. Fever, frequency, and dysuria were the most common symptoms in our study. Among the 66 asymptomatic patients, 3 were diagnosed to have UTI. Hence, asymptomatic bacteriuria is present in patients with HIV infection $(3 / 75 ; 4 \%)$ than control group $(1 / 50 ; 2 \%)$ [8]. Gugino et al. also documented the presence of asymptomatic bacteriuria in HIVinfected patients. In our study, the total number of UTI diagnosed in HIVpositive patients was $12(16 \%)$. Chi-square test reveals a statistically significant relationship between HIV status and UTI $\left(\chi^{2}=6.310, \mathrm{df}=1\right.$, $0.01<\mathrm{p}<0.02$ ). A similar study was conducted by Schonwald et al. [9] where the frequency of UTI in HIV-positive individuals was $16 \%$. In the study of De Pinho et al., UTI in AIDS patients versus asymptomatic HIVpositive individuals was $13.3 \%$ versus $3.2 \%$ [10]. According to Santos et al., bacteriuria was significantly more frequent among AIDS patients (7.6\%) than control group of HIV-negative individuals (0.91\%) [11]. The study by Marques et al. showed that UTI was more common in HIV-positive patients (6.3\%) [12]. A similar study by Evans et al. also showed the higher incidence of UTI (5.7\%) [13] among HIV-positive patients than control group.

In our study, prevalence of UTI in HIV-positive patients was more in female $(5 / 20 ; 25 \%)$ than male $(7 / 55,12.7 \%)$. In the study by Marques et al., UTI in female and male HIV-positive patients was $8.7 \%$ and $6.3 \%$, respectively. In our study, prevalence of UTI among HIV-positive patients is high $(16 \%)$, but it is within the range as described by Heyns and Fisher (7-50\%) [2]. It may be due to the fact that the rate of use of prophylactic antimicrobials for opportunistic infections is very low in this study group because of poor socioeconomic status $[14,15]$.

Among the 12 culture-positive UTI cases, 8 (66.7\%) were E. coli, followed by Klebsiella 2 (16.7\%) and Pseudomonas/S. aureus 1 (8.33\%) each (Table 5). In both symptomatic and asymptomatic groups, $E$. coli was the most predominant organism. The single isolate from HIV-negative group was also E. coli. In a similar study by De Pinho et al., E. coli was the predominant pathogen $(47.6 \%)$ among HIV-positive patients [11]. Marques et al. reported $63.1 \%$ of isolates to be E. coli and $5.3 \%$ Acinetobacter in his study but found in their study that Enterococci were the most frequent isolates in patients with HIV, whereas E. coli was most frequently isolated in controls [9]. The inference drawn in the present study is limited to a small number of patients. These findings may be useful for further exploration in a larger number of samples.

\section{SUMMARY AND CONCLUSION}

1. The study period of 1 year and 8 months revealed that it is difficult to locate/identify an HIV-positive person in a place like Kadapa on account of confidentiality/lack of awareness among the population.

2. Having identified the HIV-positive cases, collection of urine samples from the patients also needed counseling and intervention by the respective clinicians, especially when patients were not having any symptoms.

3. Follow-up of the HIV-positive cases is difficult as they lose contact with the clinicians and not traceable after being discharged from the hospital.

4. As there was difficulty in identifying the HIV-positive cases, having located a case we collected urine samples from the patients.

5. Out of 75 HIV-positive cases, 12 (16\%) are showing significant bacteriuria ( $>10^{5}$ organisms $/ \mathrm{ml}$ of urine). Among them, 9 patients have the symptoms of UTI.

6. E. coli (67\%), Klebsiella (17\%), Pseudomonas aeruginosa (8\%), and S. aureus (8\%) are the isolates from significant bacteriuria cases.

7. Out of 50 HIV-negative individuals, only $1(2 \%)$ urine sample is showing significant bacteriuria.

\section{REFERENCES}

1. Staiman VR. Urologic problems in patients with acquired immunodeficiency syndrome. Sci World J 2005;1:427-37.

2. Heyns CF, Fisher M. The urological management of the patient with acquired immunodeficiency syndrome. BJU Int 2005;95(5):709-16.

3. Kumar SS, Lakshmi P, Ananthan S. Intestinal parasitic infection in HIV infected patients in Chennai. Indian J Med Microbiol 2002;20(2):88-91.

4. Collee JG. Mackie and McCartney Practical Medical Microbiology. $14^{\text {th }}$ ed. Philadelphia, PA: Churchill Livingstone; 1996.

5. Hyun G, Lower FC. AIDS and the urologist. Urol Clin Noth Am 2003;30:101-9.

6. Muthusamy D, Rao SS, Ramani S, Monica B, Banerjee I, Abraham OC, et al. Multilocus genotyping of Cryptosporidium $\mathrm{Sp}$. Isolates from human immunodeficiency virus-infected individuals in South India. J Clin Microbiol 2006;44(2):632-4.

7. Attili SV, Gulati AK, Singh VP, Varma DV, Rai M, Sundar S. Diarrhea, CD4 counts and enteric infections in a hospital - Based cohort of HIV-infected patients around Varanasi, India. BMC Infect Dis 2006;6:39.

8. Gugino L, Russo T, Wactawski-Wende J, Goodnough SL, Tristram DA, Mylotte J. Asymptomatic bacteriuria in human immunodeficiency (HIV)-infected women. Prim Care Update Ob Gyns 1998;5(4):146.

9. Schonwald S, Begovac J, Skerk V. Urinary tract infection in HIV disease. Int J Antimicrob Agents 1999;11(3-4):309-11.

10. De Pinho AM, Lopes GS, Santos Oda R, Halpern M et al. Urinary tract infection in men with AIDS. Genitourin Med 1994;70(1):30-4.

11. Santos O da R, Bonecker C, Leite FC, Pereira AR et al. Bacteriuria in males with AIDS. Int Conf AIDS 1992;8:132.

12 Marques LP, Santos OR, Lopes GS, Rachid de Lacerda MC et al. AIDS-associated urinary tract infection. Int Conf AIDS 1989:5:234

13 Evans JK, McOwan A, Hillman RJ, Forster GE. Incidence of symptomatic UTI in HIV seropositive patients. Sex. Transm. Inf 1995;71:120-122.

14 Amutha B. Incidence of staphylococci in surgerysite infection.Int J Pharma pharmaceu Sci, 2015;(7)5

15 Tamizhazhagan V. Studies of bacterial population in ICU, Int J Pharm Pharmaceu Sci 2014;(6)4. 